\title{
Dietary patterns and their association with breast milk macronutrient composition among lactating women
}

\author{
Zhi Huang ${ }^{1}$ and Yu-ming $\mathrm{Hu}^{2^{*}} \mathrm{D}$
}

\begin{abstract}
Backgroud: Breast milk is the optimal food for infant growth and development. The purpose of this study was to evaluate the association between breast milk macronutrient composition with dietary pattern among lactating women.

Methods: A total of 220 lactating women from 2011 to 2012 in Changsha, a city of south-central China, was recruited using a multi-stage sampling method. Breast milk was collected, and the protein, fat, lactose, total dry matter, and energy contents of breast milk were measured. A $24 \mathrm{~h}$ recall method on three consecutive days was used to collect the dietary information of lactating women and an exploratory factor analysis was performed was to identify dietary patterns. The association between the concentration of a breast milk component and dietary pattern was assessed using a multivariable linear regression model.

Results: Three major dietary patterns were classified. Lactating women with dietary pattern 1 mainly ate fresh vegetables and fresh legumes. Those with dietary pattern 2 mainly ate red meat, cereals and eggs, and those with dietary pattern 3 mainly ate fungi and algae, dries legumes and soy milk. Pattern 2 was positively associated with the concentration of protein $(B=0.07,95 \% \mathrm{Cl} 0.00,0.15)$, total dry matter ( $B=$ $0.20,95 \% \mathrm{Cl} 0.02,0.38)$ and energy $(\mathrm{B}=1.66,95 \% \mathrm{Cl} 0.03,3.30)$ in breast milk. Morever, lactation period was negatively associated with the protein and total dry matter concentrations and positively associated with lactose.

Conclusions: The results show the lactation period was an important factor affecting milk composition and a dietary pattern with high intake of red meat, cereals, and eggs was associated with higher protein, total dry matter, and energy contents in breast milk. These findings show that the dietary patterns of lactating women can affect breast milk macronutrient composition and provide a foundation for improving child health.
\end{abstract}

Keywords: Dietary patterns, Breast milk, Lactating women, Macronutrient, Principal component analysis

\footnotetext{
* Correspondence: huyuming@vip.sina.com

${ }^{2}$ Department of Toxicology, Hunan Provincial Center for Disease Control and Prevention, Changsha 410005, Hunan, China

Full list of author information is available at the end of the article
}

(C) The Author(s). 2020 Open Access This article is licensed under a Creative Commons Attribution 4.0 International License, which permits use, sharing, adaptation, distribution and reproduction in any medium or format, as long as you give appropriate credit to the original author(s) and the source, provide a link to the Creative Commons licence, and indicate if changes were made. The images or other third party material in this article are included in the article's Creative Commons licence, unless indicated otherwise in a credit line to the material. If material is not included in the article's Creative Commons licence and your intended use is not permitted by statutory regulation or exceeds the permitted use, you will need to obtain permission directly from the copyright holder. To view a copy of this licence, visit http://creativecommons.org/licenses/by/4.0/. The Creative Commons Public Domain Dedication waiver (http://creativecommons.org/publicdomain/zero/1.0/) applies to the data made available in this article, unless otherwise stated in a credit line to the data. 


\section{Background}

Breast milk is the optimal food for infant growth and development. According to the World Health Organization, mothers should breastfeed infants exclusively for at least 6 months [1]. Infants benefit from breastfeeding, both in the short-term in terms of a reduced incidence and mortality rate of infectious diseases and in the long-term in terms of a reduced risk of adult obesity, diabetes, cardiovascular disease, and other metabolic diseases [2-4].

Human milk contains all the energy, macronutrients, and micronutrients required for infant growth and development during the first 4 to 6 months of life. It also provides various immunological factors and bioactive components $[2,5]$. Lactation is a critical period in terms of nutritional needs. Nutrients are required to maintain the mother's health, infant growth and health, and postpartum recovery $[6,7]$. During lactation, the macronutrient (i.e. proteins, carbohydrates, and lipids) content of human milk has large variability, which is weakly associated with the maternal diet [8]. The fatty acid composition of breast milk and its association with the maternal diet during lactation are also relevant [9-11].

Most studies have analysed the association of individual nutrients or foods with the levels of breast milk components. However, dietary intake is a combination of multiple nutrients and foods. Considering the potential for interactions between total dietary intake and foods or nutrients, dietary pattern analysis is widely used to evaluate the impact of diet on health [12-14]. Therefore, by collecting 220 breast milk samples and the dietary data of the donors in south-central China, we analysed the association of breast milk macronutrient composition (i.e. protein, fat, and lactose), total dry matter, and energy with dietary patterns among lactating women to provide a basis for further improvement of maternal and child health.

\section{Methods}

\section{Study design and population}

Breast milk samples and dietary data were collected from 2011 to 2012 in Changsha, in Hunan Province, south-central China. This city has an integrated maternal and children's health system that offers many free primary care services in local community health centres where the lactating women were recruited for our study using a multi-stage sampling method (see Fig. 1). First, considering the gross domestic product (GDP) of the nine districts of Changsha in the past year, Yuelu district with an intermediate GDP was chosen as a representative sample. After ranking all of the communities in Yuelu by income, seven communities were selected by systematic random sampling. Lastly, all of the lactating women in each community were ranked according to lactation period. In our study, the lactation period of

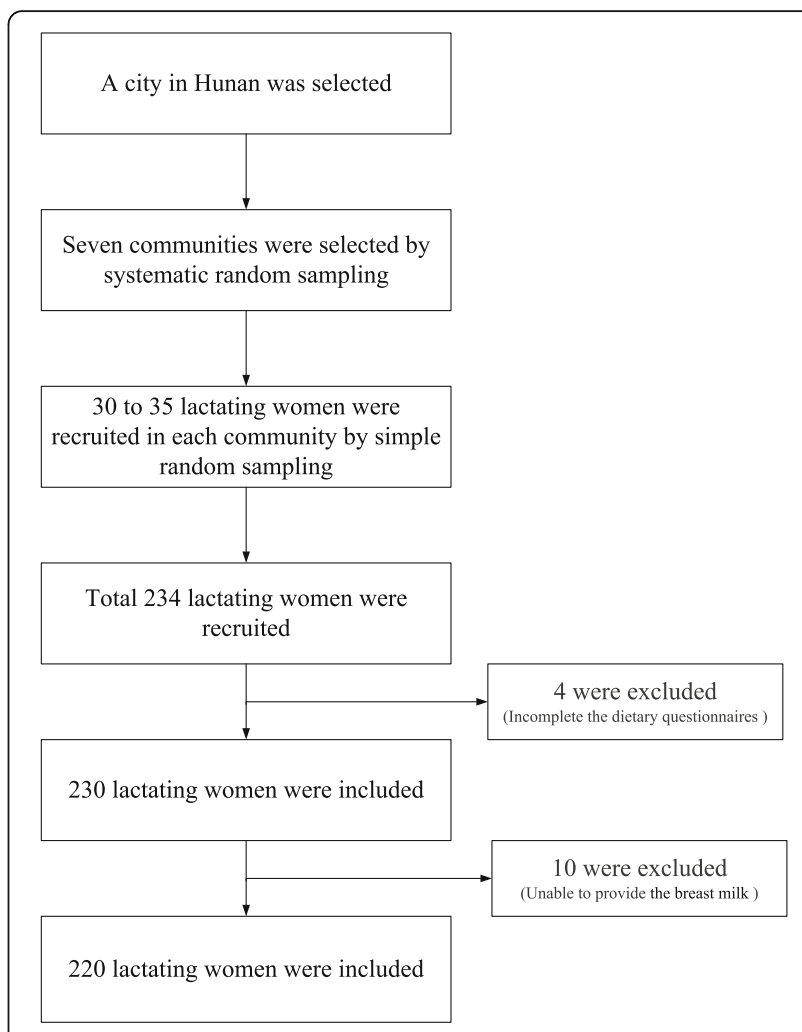

Fig. 1 The flow chart of the sampling process

women was consistent with the age of their infants; therefore, only the lactation period was analysed. In each community, 30 to 35 lactating women were selected by simple random sampling in the local maternal and children's health system. The inclusion criteria were lactating women (1) 18 to 40 years old; (2) continuing to breastfeed; (3) with self-evaluated good health; (4) no drinking alcohol or smoking; (5) single pregnancy with a term infant; (6) infant in good health; and (7) informed consent provided. Lactating women with mastitis, infectious diseases, cardiovascular diseases, metabolic diseases, nervous system diseases or cancer, and those who were unable to complete the dietary surveys or provide breast milk samples, were excluded. All lactating women were interviewed by trained interviewers in the Hunan Provincial Centre for Disease Prevention and Control and gave informed consent.

\section{Milk collection and composition analysis}

Breast milk (at least $20 \mathrm{~mL}$ ) was collected from 8 a.m. to 11 a.m. using an electric breast pump provided by our staff. The protein, fat, lactose, total dry matter, and energy contents of breast milk were measured within $4 \mathrm{~h}$ of sampling by Miris HMA, a breast milk analyser (MIRIS, Sweden). The protein, fat, lactose, and total dry matter contents of breast milk were expressed as $\mathrm{g} / 100 \mathrm{~mL}$, and $\mathrm{kcal} / 100 \mathrm{~mL}$ for energy. 


\section{Dietary assessment}

A $24 \mathrm{~h}$ recall method on three consecutive days was used to collect the dietary information of lactating women. Participants were asked to recall their detailed food intake and the estimated portion sizes over the previous three consecutive days using local weight units (1 Liang $=50 \mathrm{~g}$ ). A total of 246 foods was identified in this study, and these were classified into 23 categories based on the similarity of ingredients and the Chinese Food Composition Table [15] (Additional file 1). The questionnaires used to collect dietary data were administered in interviews by trained investigators (Additional file 2).

An exploratory factor analysis was performed to identify dietary patterns by performing a principal component analysis as described by $\mathrm{Xu}$ et al. [16]. The intake of 23 food groups was included in the factor analysis. The dietary patterns were determined by the eigenvalues $(>1)$, screen plots, factor interpretability, and variance explained. The factor loadings are equivalent to a correlation between a food item and the dietary pattern. The foods with factor loadings of $>0.2$ were considered to significantly contribute to the identified dietary pattern. Each participant was assigned a pattern-specific factor score for each dietary pattern, which was calculated as the sum of the products of the factor-loading coefficients and the standardized daily intake of each food associated with that pattern. A higher factor score in each pattern indicated that the participant was more strongly aligned with this dietary pattern. Factor scores were categorized into four quartiles, where Q1 indicates that the dietary pattern was weakly related to the dietary pattern and Q4 indicates that the dietary pattern was strongly related to the dietary pattern.

\section{Other related variables}

Sociodemographic information was collected using questionnaires, and comprised the age of lactating women, lactation period, parity (primipara and multipara), delivery mode (natural, forceps, and caesarean delivery), education level (junior or below, senior, and college or above), occupation (housework and other), and family economic status. Lactation period was subdivided into six groups (7 or fewer, $8-15,16-30,31-90,91-180$, and $181+$ days) according to the frequency distribution of all samples. Based on the per capita annual income of urban households in Hunan in 2013 [17], the total annual family income was subdivided into low $(<50$, 000 yuan), intermediate $(50,000-100,000$ yuan), and high ( $>100,000$ yuan) groups.

\section{Statistical analysis}

The statistical analysis was performed using Statistical Product and Service Solutions 13.0. The data are expressed as numbers and percentages for categorical variables. The mean (SD) was used to express continuous variables with normally distributed data, and the median (IQR) to express skewed data. The concentration of breast milk components was compared according to the characteristics of the lactating women by ANOVA. Correlation analysis with Spearman's correlation test was used to determine the correlations between lactation period and breast milk composition. Significant differences between the breast milk macronutrient composition concentrations and dietary patterns across four quartiles were assessed by ANOVA. The association between the concentration of a breast milk component and dietary pattern was assessed using a multivariate linear regression model. Significant predictors $(P<0.1)$ of breast milk macronutrient composition in bivariate analyses were included as factors in the multivariate linear regression model. B with $95 \% \mathrm{CI}$ was calculated to determine the strength of associations. $P<0.05$ was considered indicative of statistical significance.

\section{Results}

In total, 234 lactating women were invited to take part in this survey. Participants with incomplete dietary data $(n=4)$ were excluded, as were those who were unable to provide breast milk samples $(n=10)$. After exclusion, 220 lactating women were included in the analysis. The median lactation period of the subjects was 46 (IQR 14163) days, and their mean age was $27 \pm 3$ years. Table 1 lists the characteristics and concentrations of breast milk macronutrients in the lactating women. Of the lactating women, $22.27 \%$ had lactation periods over 181 days, $44.09 \%$ were 26 to 30 years old, and $79.00 \%$ were primipara. More than half of the mothers had caesarean deliveries (56.82\%), and housework as an occupation (63.64\%). Moreover, $40.91 \%$ of the mothers had a highschool senior educational level, and $46.82 \%$ had a family of middle-level economic status. The mean concentrations in breast milk were $1.37 \pm 0.73 \mathrm{~g} / 100 \mathrm{~mL}$ for protein, $3.20 \pm 1.43 \mathrm{~g} / 100 \mathrm{~mL}$ for fat, $6.51 \pm 0.40 \mathrm{~g} / 100 \mathrm{~mL}$ for lactose, $12.00 \pm 1.51 \mathrm{~g} / 100 \mathrm{~mL}$ for total dry matter, and $62.43 \pm 13.32 \mathrm{kcal} / 100 \mathrm{~mL}$ for energy.

Table 2 shows the association of the characteristics among lactating women with breast milk composition. There were significant differences in the protein $\left(\mathrm{F}_{0.05}\right.$, (5, 214) $=25.80, P<0.001)$, fat $\left(\mathrm{F}_{0.05},(5,214)=3.06, P=0.01\right)$, lactose $\left(\mathrm{F}_{0.05},(5,214)=10.81, P<0.001\right)$, total dry matter $\left(\mathrm{F}_{0.05},(5,214)=7.42, P<0.001\right)$, and energy $\left(F_{0.05}\right.$, (5, 214) $=3.49, P=0.01)$ contents of breast milk during the lactation period. The highest contents were at seven and fewer days for protein, 8-15 days for fat, total dry matter, and energy, and over 181 days for lactose. Correlation analysis showed that the lactation period was negatively correlated with the contents of protein $(\mathrm{r}=-$ $0.79, P<0.001)$, total dry matter $(r=-0.28, P<0.001)$, 
Table 1 The characteristics and concentration of breast milk among lactating women in south-central China (number of participants and percentages; $N=220$ )

\begin{tabular}{|c|c|}
\hline General characteristic & $\boldsymbol{N}(\%)$ \\
\hline \multicolumn{2}{|l|}{ Lactation period } \\
\hline 7 and below days & $31(14.09)$ \\
\hline 8 to 15 days & $34(15.45)$ \\
\hline 16 to 30 days & $34(15.45)$ \\
\hline 31 to 90 days & $32(14.55)$ \\
\hline 91 to 180 days & $40(18.18)$ \\
\hline $181 \sim$ days & $49(22.27)$ \\
\hline \multicolumn{2}{|l|}{ Age } \\
\hline 25 and below years & $87(39.55)$ \\
\hline 26 to 30 years & 97 (44.09) \\
\hline $31 \sim$ years & $36(16.36)$ \\
\hline \multicolumn{2}{|l|}{ Parity } \\
\hline Primipara & $174(79.00)$ \\
\hline Multipara & $46(21.00)$ \\
\hline \multicolumn{2}{|l|}{ Delivery mode } \\
\hline Natural & $89(40.45)$ \\
\hline Forceps & $6(2.73)$ \\
\hline Cesarean & $125(56.82)$ \\
\hline \multicolumn{2}{|l|}{ Education } \\
\hline Junior or below & $48(21.82)$ \\
\hline Senior & $90(40.91)$ \\
\hline College or above & $82(37.27)$ \\
\hline \multicolumn{2}{|l|}{ Occupation } \\
\hline Housework & $140(63.64)$ \\
\hline Others & $80(36.36)$ \\
\hline \multicolumn{2}{|l|}{ Family economic level } \\
\hline Low & $81(36.82)$ \\
\hline Middle & $103(46.82)$ \\
\hline High & $36(16.36)$ \\
\hline \multicolumn{2}{|l|}{ Breast milk composition } \\
\hline Protein (g/100 ml) Mean (SD) & $1.37(0.73)$ \\
\hline Fat (g/100 ml) Mean (SD) & $3.20(1.43)$ \\
\hline Lactose (g/100 ml) Mean (SD) & $6.51(0.40)$ \\
\hline Total dry matter (g/100 ml) Mean (SD) & $12.00(1.51)$ \\
\hline Energy (g/100Kal) Mean (SD) & $62.43(13.32)$ \\
\hline
\end{tabular}

and energy $(r=-0.16, P=0.02)$ in breast milk, but was positively correlated with the lactose content $(r=0.41$, $P<0.001)$. Moreover, the lactating women with a college education or above $\left(\mathrm{F}_{0.05,(2,217)}=3.14, P=0.04\right)$ and other $\left(\mathrm{F}_{0.05,(1,218)}=7.28, P=0.01\right)$ as an occupation were more likely to have a higher protein concentration in breast milk. The lactating women from medium-income families had a higher total dry matter concentration $\left(\mathrm{F}_{0.05},(2,217)=\right.$
4.45, $P=0.01)$ and larger amount of energy $\left(\mathrm{F}_{0.05,}(2,217)=\right.$ $4.17, P=0.02)$ in breast milk.

Figure 2 shows the results of the principal component analysis to identify dietary patterns of lactating women. Three major dietary patterns were classified by factor analysis and explained $24.84 \%$ of the dietary intake variance. Dietary pattern 1 had high intake of fresh vegetables (leafy and non-leafy) and fresh legumes, but low intake of poultry, organ meats, and eggs. Dietary pattern 2 had high intake of red meat, cereals, and eggs, but lower intake of animal milk, nuts and seeds, candy, and fast food. Dietary pattern 3 had high intakes of fungi and algae, dried legumes, and soy milk, and lower intakes of starchy roots and tubers, fresh legumes, and rice.

Table 3 shows the breast milk composition by quartile categories of dietary patterns. The lactating women in the top quartile $(\mathrm{Q} 4)$ of pattern 1 had lower concentrations of protein $\left(\mathrm{F}_{0.05},(3,216)=12.04, P<0.001\right)$ and total dry matter $\left(\mathrm{F}_{0.05},(3,216)=2.88, P=0.04\right)$ in breast milk, while those in pattern 2 had higher concentrations of protein $\left(\mathrm{F}_{0.05},(3,216)=6.09, P<0.001\right)$ and total dry matter $\left(\mathrm{F}_{0.05},(3,216)=3.98, P=0.01\right)$. There were significant differences in the lactose $\left(\mathrm{F}_{0.05},(3,216)=7.32, P<0.001\right)$ level of breast milk among the quartiles of pattern 1; a higher dietary pattern score was associated with a higher lactose concentration. There were no significant differences in the fat and energy levels of breast milk across quartiles of the three patterns.

Table 4 presents the associations between dietary patterns and breast milk composition based on multivariate analysis. Overall, pattern 2 was positively associated with the concentrations of protein $(B=0.07,95 \%$ CI 0.00 , $0.15)$, total dry matter $(B=0.20,95 \%$ CI $0.02,0.38)$, and energy $(B=1.66,95 \%$ CI $0.03,3.30)$ in breast milk. Dietary patterns 1 and 3 were not significantly associated with the macronutrient concentrations in breast milk. Moreover, lactation period was negatively associated with the protein and total dry matter concentrations and positively associated with lactose in the multivariate linear regression model of associations between dietary patterns and breast milk concentration.

\section{Discussion}

We report here an association between maternal dietary pattern and breast milk macronutrient composition. The results showed that there are three major dietary patterns among lactating women in south-central China: dietary pattern 1 was mainly based on fresh vegetables and fresh legumes; dietary pattern 2 on red meat, cereals, and eggs; and dietary pattern 3 was based on fungi and algae, dried legumes, and soy milk. Moreover, the protein, total dry matter, and energy concentrations in breast milk were related to the dietary pattern. 


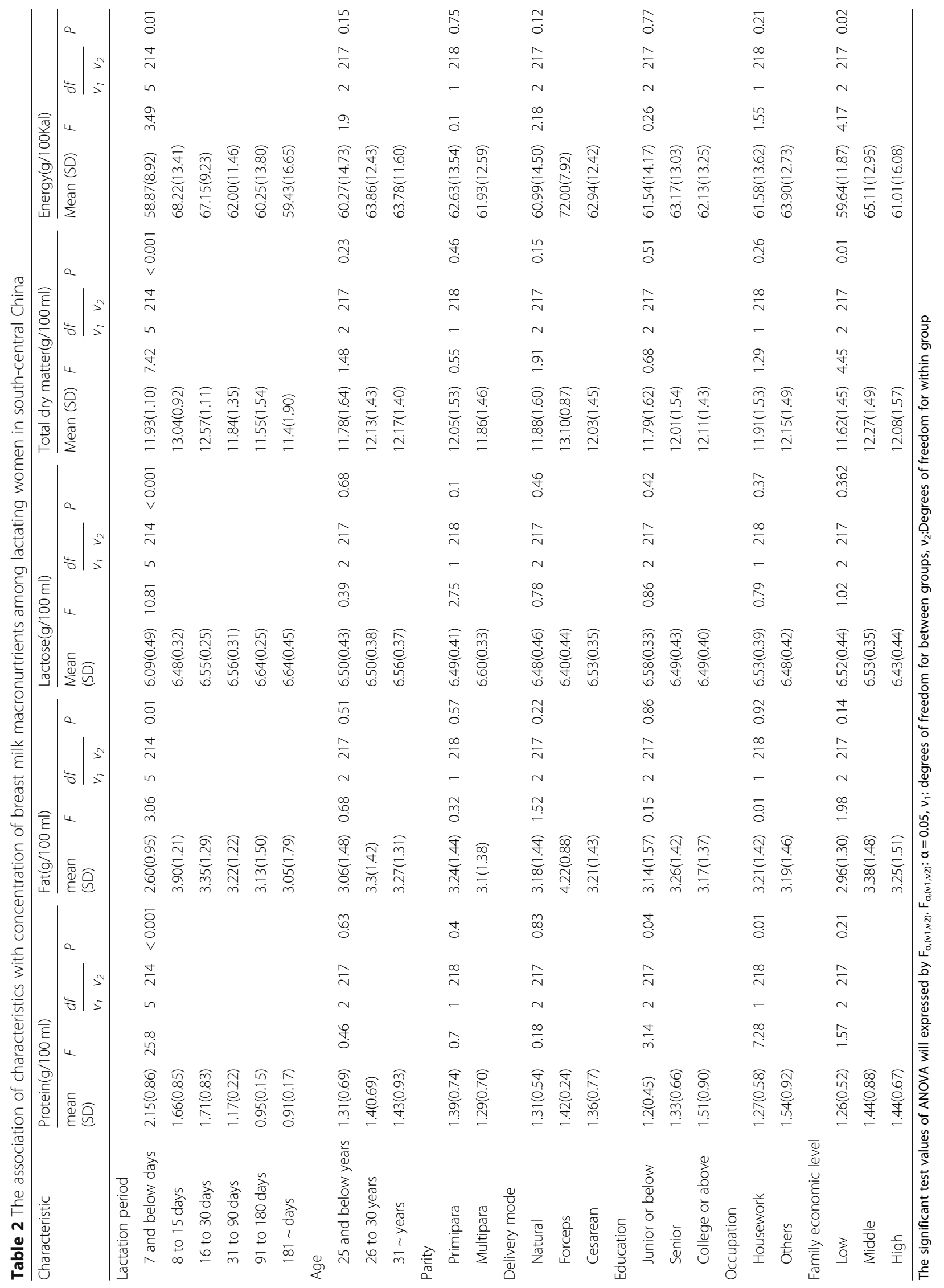



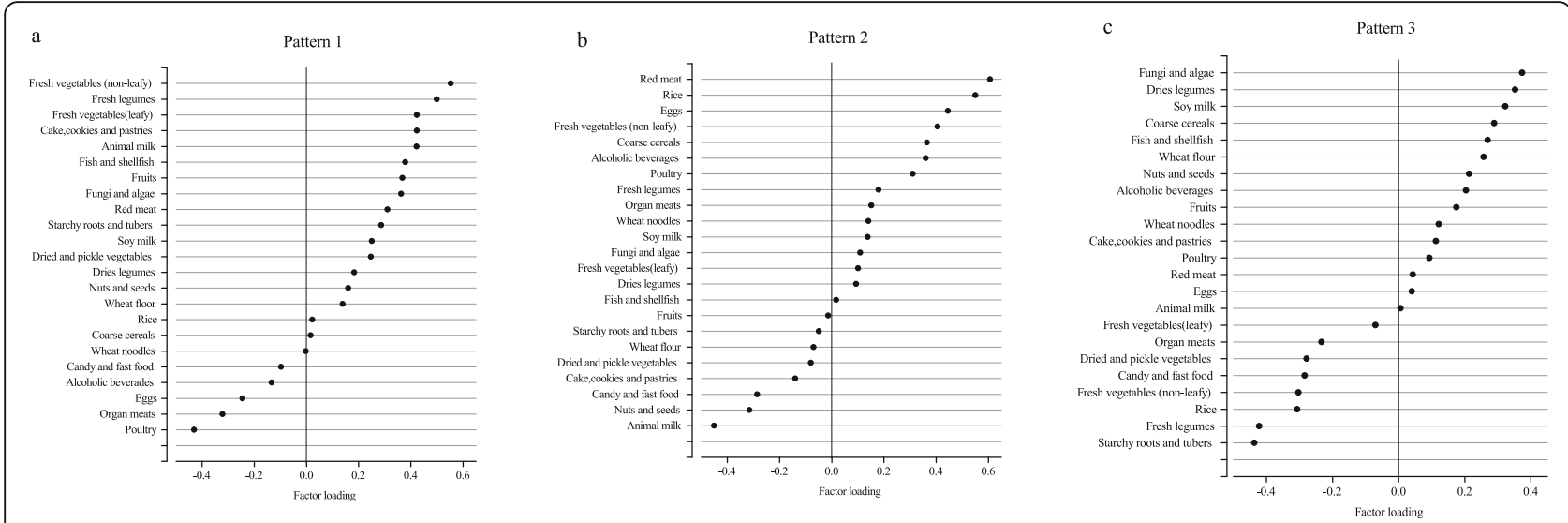

Fig. 2 Factor loadings for three dietary patterns among lactating women in south-central China $(N=220)$. (Factor loadings of $>|0.20|$ represent the foods which most strongly related to the identified factor). $\mathbf{a}$ : Factor loadings for pattern $1 ; \mathbf{b}$ : Factor loadings for pattern 2; $\mathbf{c}$ : Factor loadings for pattern 3

Macronutrients such as protein, fat, and carbohydrates are the main nutrients in breast milk. In this study, the concentrations in breast milk within 12 months of delivery were $1.37 \pm 0.73 \mathrm{~g} / 100 \mathrm{~mL}$ for protein, $3.20 \pm 1.43 \mathrm{~g} / 100 \mathrm{~mL}$ for fat, and $6.51 \pm 0.40 \mathrm{~g} / 100 \mathrm{~mL}$ for lactose. Yang et al. reported that the concentrations in breast milk within 2 to
4 months of delivery in eastern China were $0.8 \pm 0.1 \mathrm{~g} / 100$ $\mathrm{mL}$ for protein, $3.1 \pm 1.4 \mathrm{~g} / 100 \mathrm{~mL}$ for fat, and $7.2 \pm 0.3 \mathrm{~g} /$ $100 \mathrm{~mL}$ for lactose [8]. Cao et al. reported that the concentrations in breast milk within 15 months of delivery in Shanxi Province [18] were $1.5 \pm 0.5 \mathrm{~g} / 100 \mathrm{~mL}$ for protein, $5.9 \pm 2.1 \mathrm{~g} / 100 \mathrm{~mL}$ for fat, and $6.6 \pm 1.5 \mathrm{~g} / 100 \mathrm{~mL}$ for

Table 3 The breast milk macronutrients composition concentrations (Mean \pm SD) of lactating women by quartile categories of dietary patterns

\begin{tabular}{|c|c|c|c|c|c|c|c|c|}
\hline & \multirow[t]{2}{*}{ Q1 } & \multirow[t]{2}{*}{ Q2 } & \multirow[t]{2}{*}{ Q3 } & \multirow[t]{2}{*}{ Q4 } & \multirow[t]{2}{*}{$\mathrm{F}$} & \multicolumn{2}{|l|}{$d f$} & \multirow[t]{2}{*}{ P } \\
\hline & & & & & & $v_{1}$ & $v_{2}$ & \\
\hline$N$ & 55 & 55 & 55 & 55 & & & & \\
\hline \multicolumn{9}{|l|}{ Pattern 1} \\
\hline Protein & 1.79(0.79) & 1.43(0.83) & $1.20(0.61)$ & $1.06(0.42)$ & 12.04 & 3 & 216 & $<0.001$ \\
\hline Fat & $3.30(1.17)$ & $3.23(1.51)$ & $3.10(1.45)$ & $3.18(1.58)$ & 0.19 & 3 & 216 & 0.90 \\
\hline Lactose & $6.32(0.43)$ & $6.49(0.48)$ & $6.61(0.31)$ & $6.62(0.27)$ & 7.32 & 3 & 216 & $<0.001$ \\
\hline Total dry matter & $12.45(1.10)$ & $12.07(1.66)$ & $11.76(1.51)$ & $11.71(1.64)$ & 2.88 & 3 & 216 & 0.04 \\
\hline Energy & 63.79(12.34) & $63.00(13.46)$ & $61.47(13.10)$ & $61.44(14.51)$ & 0.42 & 3 & 216 & 0.74 \\
\hline \multicolumn{9}{|l|}{ Pattern 2} \\
\hline Protein & $1.16(0.39)$ & $1.29(0.72)$ & $1.31(0.53)$ & $1.71(1.03)$ & 6.09 & 3 & 216 & $<0.001$ \\
\hline Fat & $2.93(1.30)$ & $3.15(1.41)$ & $3.52(1.60)$ & $3.21(1.36)$ & 1.58 & 3 & 216 & 0.19 \\
\hline Lactose & $6.50(0.45)$ & $6.52(0.47)$ & $6.56(0.28)$ & $6.46(0.37)$ & 0.56 & 3 & 216 & 0.64 \\
\hline Total dry matter & $11.49(1.36)$ & $11.86(1.62)$ & $12.30(1.64)$ & $12.33(1.30)$ & 3.98 & 3 & 216 & 0.01 \\
\hline Energy & $58.96(12.07)$ & $61.69(13.08)$ & $64.34(16.30)$ & $64.71(10.74)$ & 2.25 & 3 & 216 & 0.08 \\
\hline \multicolumn{9}{|l|}{ Pattern 3} \\
\hline Protein & $1.21(0.69)$ & $1.39(0.72)$ & $1.31(0.39)$ & $1.57(0.97)$ & 2.54 & 3 & 216 & 0.06 \\
\hline Fat & $3.47(1.40)$ & $3.06(1.50)$ & $3.38(1.32)$ & $2.90(1.45)$ & 2.02 & 3 & 216 & 0.11 \\
\hline Lactose & $6.52(0.33)$ & $6.50(0.42)$ & $6.46(0.49)$ & $6.57(0.34)$ & 0.76 & 3 & 216 & 0.52 \\
\hline Total dry matter & $12.13(1.49)$ & $11.85(1.55)$ & $12.08(1.49)$ & $11.93(1.55)$ & 0.40 & 3 & 216 & 0.75 \\
\hline Energy & $64.40(12.58)$ & $61.31(13.14)$ & $62.34(14.62)$ & $61.65(13.00)$ & 0.59 & 3 & 216 & 0.62 \\
\hline
\end{tabular}

The significant test values of ANOVA will expressed by $F_{a,(v 1, v 2)} . F_{a,(v 1, v 2)}: a=0.05, v_{1}$ : degrees of freedom for between groups, $v_{2}$ :Degrees of freedom for within groups 
lactose. Huang et al. reported that the concentrations in breast milk within 9 months of delivery in Sichuan Province [19] were 1.14 (range 1.09-1.19) g/100 mL for protein, $4.1 \pm 1.6 \mathrm{~g} / 100 \mathrm{~mL}$ for fat, and 7.19 (range $6.78-7.42$ ) g/100 $\mathrm{mL}$ for lactose. This suggests that the macronutrient concentrations in breast milk vary geographically (Table 5).

In addition, the concentrations of protein, fat, and lactose differed significantly with the stage of lactation in bivariate analyses in our study. The lactation stage is the factor that affects milk composition most strongly; this has been shown in several studies $[8,20]$. In our multivariate analysis, lactation period was negatively associated with the protein concentration, but positively associated with lactose, which is consistent with previous studies $[5,8]$. However, no association was found between the fat concentration and lactation period in the multivariate analysis, which is inconsistent with other reports that the fat content declined with the lactation period [8].

Many recent studies have reported associations between the maternal diet and milk macronutrient composition. Some studies reported a positive effect of maternal diet on breast milk composition, while others showed the opposite [21]. In our study, the protein concentration and energy in breast milk were positively related to dietary pattern 2 . Pattern 2 was characterized by high intakes of red meat, cereals, and eggs. Red meat is a high-energy-density food that contains large amounts of saturated fatty acids and cholesterol, so a high intake may lead to excessive energy intake [22]. Venus et al. reported a correlation between the total protein concentration in human milk and maternal daily energy and fat intakes [23]. Protein is important for physical growth and brain development of neonates, especially premature infants who need more protein for growth and development; however, the breast milk protein content in these mothers decreased more with the lactation period than in term infants [24]. Therefore, a rational dietary pattern for lactating women will be an effective way to improve infant nutrition.

The total dry matter content of breast milk is important for promoting infant growth and development. Wu et al. reported that the higher the total dry matter content of breast milk, the greater the height of the infant [25]. However, few studies have focused on the association of total dry matter concentration in breast milk with dietary intake. We found that dietary pattern 2 (high intake of red meat, cereals, and eggs) was associated with the total dry matter content of breast milk. Therefore, the maternal dietary pattern may influence the total dry matter content of breast milk.

Fat is a major source of energy in human milk. Several studies found positive associations between dietary fatty acid intake and the fatty acid concentration in breast milk $[10,21,26]$, while others reported no such association [27, 28]. In the current study, the pattern was not significantly associated with the fat concentration in breast milk. Lactose is the principal carbohydrate in breast milk. According to Wang et al., the lactose concentration in the breast milk of vegetarian lactating women was significantly lower than that of meat-eaters [29]. However, the lactose concentration in breast milk was not associated with the maternal diet in our study.

Table 5 Comparing to the breast milk macronutrients concentration in different areas of China

\begin{tabular}{lllll}
\hline Area & $\boldsymbol{N}$ & Lactation period & Method & Concentration (Mean \pm SD or Median (IQR),g/100 mL) \\
\hline $\begin{array}{llll}\text { Protein } \\
\text { Our study }\end{array}$ & 220 & 0 to 12 months & Miris human milk analyzer & $1.37 \pm 0.73$ \\
$\begin{array}{l}\text { East of China [9] } \\
\text { Shanxi [20] }\end{array}$ & 90 & 2 to 4 months & Miris human milk analyzer & $0.8 \pm 0.1$ \\
Sichuan [21] & 4317 & 0 to 15 months & Miris human milk analyzer & $1.5 \pm 0.5$ \\
Fat & 60 & 0 to 9 months & Miris human milk analyzer & $1.14(1.09,1.19)$ \\
Our study & 220 & 0 to 12 months & Miris human milk analyzer & $3.2 \pm 1.43$ \\
East of China & 90 & 2 to 4 months & Miris human milk analyzer & $3.1 \pm 1.4$ \\
Shanxi & 4317 & 0 to 15 months & Miris human milk analyzer & $5.9 \pm 2.1$ \\
Sichuan & 60 & 0 to 9 months & Miris human milk analyzer & $4.1 \pm 1.6$ \\
Lactose & & & & \\
Our study & 220 & 0 to 12 months & Miris human milk analyzer & $6.51 \pm 0.40$ \\
East of China & 90 & 2 to 4 months & Miris human milk analyzer & $7.2 \pm 0.3$ \\
Shanxi & 4317 & 0 to 15 months & Miris human milk analyzer & $6.6 \pm 1.5$ \\
Sichuan & 60 & 0 to 9 months & Miris human milk analyzer & $7.19(6.78,7.42)$ \\
\hline
\end{tabular}

${ }^{a}$ : The breast milk composition represented three cities from east of China, including Beijing, Guangzhou and Suzhou 
Previous studies have shown that economic status is strongly associated with maternal diet, where family income influences the variety and quantity of food intake. Li et al. reported that family economic status was related to fruit intake in mothers [30], while Wang et al. reported that family economic status was positively correlated with the dietary diversity of mothers [31]. However, in this study multivariate analysis showed no association between dietary patterns and family economic status. This finding may be attributed to the similar demographic characteristics of participants, as they were all recruited from one city. Therefore, the effect of economic status on maternal dietary patterns should be considered in future studies.

This study had several highlights and limitations. First, to our knowledge, this is the first study of the macronutrient composition of breast milk of lactating women and its association with dietary pattern in south-central China, so the findings provide a valuable basis for improving maternal nutrition and infant feeding in this region. Second, we performed a principal component analysis to analyse dietary patterns, taking into account overall food intake and food interactions. Nevertheless, this study also had shortcomings. First, we used the $24 \mathrm{~h}$ recall method to collect dietary information, which may be subject to recall bias. Second, a small number of lactating women was found in the local communities and some were reluctant to enrol in the study. In total, only 220 lactating women were recruited. The sample size is too small to represent the general population, which may limit the generalizability of our findings. Third, we analysed only the association between macronutrients in breast milk and the dietary pattern. While micronutrients such as vitamins and minerals are also important components of breast milk, their contents may be affected by dietary intake [32-35], so their associations need to be clarified in future studies.

\section{Conclusion}

Three major dietary patterns were identified among lactating women in south-central China. Lactation period was an important factor affecting milk composition and a dietary pattern with high intake of red meat, cereals, and eggs was associated with higher protein, total dry matter, and energy contents in breast milk. These findings show that the dietary patterns of lactating women can affect breast milk macronutrient composition and provide a foundation for improving child health.

\section{Supplementary information}

Supplementary information accompanies this paper at https://doi.org/10. 1186/s13006-020-00293-w.

Additional file 1: Table S1. Food grouping used in the dietary pattern analyses.

Additional file 2. Lactating women dietary questionnaire.

\section{Abbreviations}

$\mathrm{N}$ : Number of participants; ANOVA: Variance analyses; SD: Standard deviation; IQR: interquartile range; B: Unstandardized coefficients; Cl: Confidence interval.

\section{Acknowledgements}

We thank the participants for their assistance and support.

\section{Authors' contributions}

$\mathrm{ZH}$ and $\mathrm{YH}$ conceived the research idea, collected the data. $\mathrm{ZH}$ performed the statistical analyses and drafted the manuscript. YH provided the critical review of the manuscript. All authors approved the final version.

\section{Funding}

Self-funded.

\section{Availability of data and materials}

The datasets used and/or analyzed during the current study are available from the corresponding author on reasonable request.

\section{Ethics approval and consent to participate}

The study procedure was approved by the ethics committee of Hunan Provincial Centre for Disease Prevention and Control. Written informed consent was obtained from all participants.

\section{Consent for publication}

Not applicable.

\section{Competing interests}

The authors declare that they have no competing interests.

\section{Author details}

${ }^{1}$ Hunan University of Medicine, No. 492 Jinxi South Road, Huaihua 418000, Hunan, China. ${ }^{2}$ Department of Toxicology, Hunan Provincial Center for Disease Control and Prevention, Changsha 410005, Hunan, China.

Received: 10 August 2019 Accepted: 18 May 2020

Published online: 05 June 2020

\section{References}

1. World Health Organization Global Strategy for Infant and Young Child Feeding 2003. https://www.who.int/maternal_child_adolescent/documents/ 9241562218/en/.

2. Boix-Amoros A, Collado MC, Van't Land B, Calvert A, Le Doare K, Garssen J, et al. Reviewing the evidence on breast milk composition and immunological outcomes. Nutr Rev. 2019:77(8):541-56.

3. Penacoba C, Catala P. Associations between breastfeeding and motherinfant relationships: a systematic review. Breastfeed Med. 2019;14(9):616-29.

4. Lee MK, Binns C. Breastfeeding and the risk of infant illness in Asia: a review. Int J Environ Res Public Health. 2019;17(1):186.

5. Yang T, Zhang L, Bao W, Rong S. Nutritional composition of breast milk in Chinese women: a systematic review. Asia Pac J Clin Nutr. 2018;27(3):491502.

6. Koletzko B, Godfrey KM, Poston L, Szajewska H, van Goudoever JB, de Waard $\mathrm{M}$, et al. Nutrition during pregnancy, lactation and early childhood and itsimplications for maternal and long-term child health: the early nutrition project recommendations. Ann Nutr Metab. 2019;74(2):93-106.

7. Yaya S, Wang R, Tang S, Ghose B. Intake of supplementary food during pregnancy and lactation and its association with child nutrition in Timor Leste. PeerJ. 2018;6:e5935.

8. Yang $T$, Zhang $Y$, Ning $Y$, You L, Ma D, Zheng $Y$, et al. Breast milk macronutrient composition and the associated factors in urban Chinese mothers. Chin Med J. 2014;127(9):1721-5.

9. Bravi F, Wiens F, Decarli A, Dal Pont A, Agostoni C, Ferraroni M. Impact of maternal nutrition on breast-milk composition: a systematic review. Am J Clin Nutr. 2016;104(3):646-62

10. Tian HM, Wu YX, Lin YQ, Chen XY, Yu M, Tong L, et al. Dietary patterns affect maternal macronutrient intake levels and the fatty acid profile of breast milk in lactating Chinese mothers. Nutrition. 2019;58:83-8. 
11. Liu Y, Liu X, Wang L. The investigation of fatty acid composition of breast milk and its relationship with dietary fatty acid intake in 5 regions of China. Medicine (Baltimore). 2019;98(24):e15855.

12. Margerison C, Riddell $L$, McNaughton SA, Nowson CA. Associations between dietary patterns and blood pressure in a sample of Australian adults. Nutr J. 2020;19(1):5.

13. Dalrymple KV, Flynn AC, Seed PT, Briley AL, O'Keeffe M, Godfrey KM, et al. Associations between dietary patterns, eating behaviours, and body composition and adiposity in 3-year-old children of mothers with obesity. Pediatr Obes. 2019;15(5):e12608.

14. Ma E, Ohira T, Sakai A, Yasumura S, Takahashi A, Kazama J, et al. Associations between dietary patterns and cardiometabolic risks in Japan: a crosssectional study from the Fukushima health management survey, 2011-2015. Nutrients. 2020;12(1):129.

15. Yang YX, GYW. China food composition. 2nd ed. China: Peking University Medical Press; 2009.

16. Xu X, Hall J, Byles J, Shi Z. Dietary pattern is associated with obesity in older people in China: data from China health and nutrition survey (CHNS). Nutrients. 2015;7(9):8170-88.

17. Hunan Provincail Bureau of Statistics. Hunan statistics yearbook. Beijing: China Statistic Press; 2013. p. 2013

18. Cao MH, An Q, Li Y, Yao DL. Analysis of the detection results of 4317 cases of breast milk composition in Weinan city. Chinese J Child Health Care. 2016;24(7):739-41.

19. Huang LL, Xiong F, Yang F. Relationship between breast milk composition and weight growth velocity of infants fed with exclusive breast milk. Chinese J Contemp Pediatr. 2016;18(10):943-6.

20. Sun $Y$, Han YB, Jiang HY, He HY. Analysis of breast milk composition. Matern Child Health Care China. 2018;33(11):2637-9.

21. Keikha M, Bahreynian M, Saleki M, Kelishadi R. Macro- and micronutrients of human milk composition: are they related to maternal diet? A comprehensive systematic review. Breastfeed Med. 2017:12(9):517-27.

22. Shu L, Zheng PF, Zhang XY, Si CJ, Yu XL, Gao W, et al. Association between dietary patterns and the indicators of obesity among Chinese: a crosssectional study. Nutrients. 2015;7(9):7995-8009.

23. Leelahakul V, Tanaka F, Sinsuksai N, Vichitsukon K, Pinyopasakul W, Kido N, et al. Comparison of the protein composition of breast milk and the nutrient intake between Thai and Japanese mothers. Nurs Health Sci. 2009; 11(2):180-4

24. Kreissl A, Zwiauer V, Repa A, Binder C, Thanhaeuser M, Jilma B, et al. Human milk analyser shows that the lactation period affects protein levels in preterm breastmilk. Acta Paediatr. 2016;105(6):635-40.

25. Wu YP, Guo CQ, Chu YJ, Liu XZ. Cohort study on the effect of breast milk composition on early growth and development velocity of infants fed with exclusive breastfeeding. Matern Child Health Care China. 2014; 29(22):3600-2.

26. Kim H, Kang S, Jung BM, Yi H, Jung JA, Chang N. Breast milk fatty acid composition and fatty acid intake of lactating mothers in South Korea. Br J Nutr. 2017:117(4):556-61.

27. Iranpour R, Kelishadi R, Babaie S, Khosravi-Darani K, Farajian S. Comparison of long chain polyunsaturated fatty acid content in human milk in preterm and term deliveries and its correlation with mothers' diet. J Res Med Sci. 2013;18(1):1-5

28. Kelishadi R, Hadi B, Iranpour R, Khosravi-Darani K, Mirmoghtadaee P, Farajian $\mathrm{S}$, et al. A study on lipid content and fatty acid of breast milk and its association with mother's diet composition. J Res Med Sci. 2012; 17(9):824-7.

29. Wang BZ, Sun YJ, Zhang $H$. Analysis of breast milk composition and it's impactors. Ningxia Med J. 2016;38(8):758-60.

30. Bo LG, Lin Q, Ping O, Xian XR. Analysis on dietary survey and influencing factors of wet nurses during puerperal period. Chinese J Matern Child Health. 2015;30(18):3029-31.

31. Lei WW, Hui LX, Yang YX. The diet of lactating mothers and its influencing factors in Zhuhai. Chinese J Mater Child Health. 2013:18(12):1942-4.

32. Valent F, Horvat M, Mazej D, Stibilj V, Barbone F. Maternal diet and selenium concentration in human milk from an Italian population. J Epidemiol. 2011; 21(4):285-92.

33. Deegan $\mathrm{KL}$, Jones $\mathrm{KM}$, Zuleta $\mathrm{C}$, Ramirez-Zea $\mathrm{M}$, Lildballe $\mathrm{DL}$, Nexo $\mathrm{E}$, et al. Breast milk vitamin B-12 concentrations in Guatemalan women are correlated with maternal but not infant vitamin B-12 status at 12 months postpartum. J Nutr. 2012;142(1):112-6.
34. Maru M, Birhanu T, Tessema DA. Calcium, magnesium, iron, zinc and copper, compositions of human milk from populations with cereal and 'enset' based diets. Ethiop J Health Sci. 2013;23(2):90-7.

35. Choi YK, Kim JM, Lee JE, Cho MS, Kang BS, Choi H, et al. Association of maternal diet with zinc, copper, and iron concentrations in transitional human milk produced by Korean mothers. Clin Nutr Res. 2016;5(1):15-25.

\section{Publisher's Note}

Springer Nature remains neutral with regard to jurisdictional claims in published maps and institutional affiliations.
Ready to submit your research? Choose BMC and benefit from:

- fast, convenient online submission

- thorough peer review by experienced researchers in your field

- rapid publication on acceptance

- support for research data, including large and complex data types

- gold Open Access which fosters wider collaboration and increased citations

- maximum visibility for your research: over $100 \mathrm{M}$ website views per year

At $\mathrm{BMC}$, research is always in progress.

Learn more biomedcentral.com/submissions 